\title{
DINÁMICAS DE URBANIZACIÓN TURÍSTICA EN EL LITORAL DE BUENOS AIRES, ARGENTINA
}

\author{
Lorena Soledad Beier* \\ Universidad Provincial del Sudoeste. Bahía Blanca. Buenos Aires. Argentina \\ https://orcid.org/0000-0003-4631-426X \\ Salvador Anton Clavé** \\ Universidad Rovira i Virgili. Cataluña. España \\ https://orcid.org/0000-0001-9818-2778 \\ Hernán Pedro Vigier*** \\ Universidad Provincial del Sudoeste. Bahía Blanca. Buenos Aires. Argentina \\ https://orcid.org/0000-0003-0774-8620
}

\section{RESUMEN}

El objetivo del presente trabajo es discutir el papel y el alcance del turismo en los procesos de urbanización del litoral en Argentina y, por extensión, en Latinoamérica. Para ello, se identifican grupos de ciudades en el litoral de Buenos Aires según su dinámica turística de acuerdo a los cambios y continuidades demográficas y económicas que han experimentado durante el periodo $2001-2010$.

Los resultados obtenidos permiten entender de manera contextualizada la naturaleza y funcionalidad turística y urbana de las diferentes ciudades del litoral de la provincia. Así, se han identificado seis grupos de ciudades según los procesos de cambio que ha provocado en ellas el turismo y se ha evidenciado la diversidad, complejidad y dinamismo que presenta cada tipo de conglomerado según sus características particulares. Todo ello ha permitido visualizar la diversidad de destinos que existen en el litoral de la provincia según su situación urbana particular y su evolución turística reciente.

Por último, se ofrecen evidencias empíricas que respaldan la concepción que el turismo no solamente tiene efectos diferenciales en los procesos de urbanización, sino que, en función de las circunstancias locales, genera dinámicas específicas que deben explicarse a partir del conocimiento de la realidad económica y la identidad de cada lugar.

Fecha de recepción: 24 de junio de 2019

Fecha de aceptación: 18 de marzo de 2020

* Centro de Emprendedorismo y Desarrollo Territorial Sostenible, CEDETS, (UPSO-CIC). Bahía Blanca (Argentina); Departament de Geografia. Universitat Rovira i Virgili. Cataluña. España. E-mail: lbeier@upso.edu.ar ** Departament de Geografia. Universitat Rovira i Virgili. Cataluña. España. E-mail: salvador.anton@urv.cat

*** Centro de Emprendedorismo y Desarrollo Territorial Sostenible, CEDETS, (UPSO-CIC). Departamento de Economía. Universidad Nacional del Sur. Bahía Blanca. Argentina. E-mail: hvigier@upso.edu.ar 
Palabras clave: urbanización turística; movilidad turística; desarrollo urbano.

Dynamics of tourist urbanization on the coast of Buenos Aires, Argentina

\begin{abstract}
The aim of this paper is to discuss the role and the impact of tourism in Argentina's and thus Latin America's coastal urban development processes. Hence, groups of cities with different tourism dynamics are identified on the coast of Buenos Aires according to their demographic and economic changes and continuities during the period 2001-2010.

The results allow us to understand in a contextualized way the nature and tourist and urban functionality of the different cities on the coast of the province. Thus, six groups of cities have been identified according to the processes of change that tourism has caused in them and the diversity, complexity and dynamism that each type of cluster presents according to its particular characteristics has been evidenced. All this has allowed to visualize the diversity of destinations that exist in the littoral of the province according to its particular urban situation and its recent tourist evolution.

Finally, empirical evidence is offered to support the conception that tourism not only has differential effects on urbanization processes, but that, depending on local circumstances, it generates specific dynamics that must be explained based on the knowledge of the economy and the identity of each place.
\end{abstract}

Keywords: tourism urbanization; tourist mobility; urban development.

\title{
1. INTRODUCCIÓN
}

Según datos del Foro Nacional del Turismo (2017), el turismo aportó a la economía nacional argentina más de un millón de empleos en 2016. Esta cifra resulta de la llegada al país de 5,6 millones de turistas extranjeros y de los 43,4 millones de viajes que hicieron los propios argentinos en el país. Como resultado de esta actividad, el turismo genera en Argentina un 7,2\% del PIB. Se trata, demás, de una actividad en continua expansión y diversificación.

Más allá de su impacto macroeconómico, el turismo es una actividad que influye y es afectada por el desarrollo urbano en la medida que a través de la atracción de visitantes y residentes cataliza el crecimiento de los espacios y transforma a las comunidades locales y a su identidad. En este contexto, resulta de interés conocer qué efectos tiene el turismo sobre el sistema urbano argentino y, más específicamente, de la provincia de Buenos Aires. Así, se pretende discutir el papel y el alcance del turismo en los procesos de urbanización del litoral en Argentina y, por extensión, en Latinoamérica.

Más en detalle, se propone analizar la heterogeneidad de los procesos de urbanización turística y de sus efectos sobre los municipios litorales de la Provincia de Buenos Aires. Para ello se revisan, en primer lugar, los estudios disponibles hasta el momento acerca del alcance y las características de los procesos de urbanización turística en Latinoamérica y, en particular, en la costa bonaerense. Se plantea, a continuación, la existencia de diferentes 
procesos de evolución urbana en los municipios litorales de la provincia de Buenos Aires mediante el estudio de variables demográficas y económicas en el periodo $2001-2010$, según datos obtenidos a partir del Censo Nacional de Población, Hogares y Viviendas realizado por INDEC, y, finalmente, se discuten las características y la naturaleza de las diferentes dinámicas de urbanización observadas valorando el papel que ha tenido en cada una tanto la atracción de turistas como de nuevos residentes.

El fundamento teórico de este artículo se basa en el concepto de urbanización turística. Se entiende como tal al fenómeno urbano diferencial que provoca la tracción de residentes hacia destinos turísticos. Mullins (1991) lo define como el proceso por el cual las ciudades son construidas o reconstruidas específicamente por el turismo generando localidades que se diferencian del resto por tener, entre otros aspectos, mayor densidad de viviendas, mayores tasas de crecimiento demográfico, mayor proporción de población vieja y de recién llegados, predominio de parejas como tipología familiar, y un ritmo de creación de puestos de trabajo más alto, así como también es más alto el nivel de desempleo.

De esta manera, se define como objetivo general analizar la evolución de los destinos turísticos costeros de la provincia de Buenos Aires considerando a la actividad turística como catalizadora de su crecimiento urbano y comprender las dinámicas y tipologías de los procesos de urbanización turística ocurridos en este territorio“, siendo los objetivos particulares los siguientes:

- Caracterizar a las ciudades que integran los municipios costeros de la provincia de Buenos Aires, basada en la identificación de su condición turística y los aspectos urbanos, socioeconómicos y demográficos.

- Analizar el comportamiento de las ciudades turísticas respecto al resto y estudiar su transformación a partir de la evolución en el tiempo.

- Incorporar el análisis de la evolución de las condiciones del destino turístico como sistema urbano.

Asimismo, se proponen las siguientes hipótesis de trabajo:

H1-Las ciudades turísticas basan su desarrollo en la existencia de un atractivo turístico que genera una alta tasa de función turística.

H2- La actividad turística conlleva la atracción de residentes y el crecimiento demográfico.

H3-Las ciudades turísticas tienen tendencia a tener una población joven.

H4- A mayor crecimiento turístico, mayor asentamiento de mano de obra no calificada, y menor calidad habitacional de los hogares. Esta es, sin embargo, una situación que evoluciona y que puede llegar a estabilizarse en el tiempo.

H5-Las ciudades turísticas presentan un elevado índice de actividad debido a que el turismo contribuye a la generación y el crecimiento de empleo.

\section{ANTECEDENTES}

En este artículo se plantea conocer cómo el turismo configura dinámicas de urbanización a partir del análisis específico de los municipios costeros de la provincia de Buenos Aires. Trata de reflexionar, por lo tanto, a partir de la colección de evidencias empíricas, acerca de la construcción social del espacio resultante de un estilo de vida, el de los grupos sociales con 
capacidad para moverse por motivos de ocio, que es cada vez más generalizado. Se analizan, en consecuencia, estructuras urbanas que, en palabras de Olano (2019) no pre-existen a las prácticas que los individuos realizan en ellas sino que son desarrolladas precisamente a consecuencia de su carácter simbólico como espacios de ocio. Lo característico de tales espacios es, en particular, que se definen y se estructuran precisamente por el uso, la apropiación, el significado y las prácticas cotidianas que, junto a los residentes, los turistas realizan en ellos (Stock, 2015). En este artículo, se plantea en definitiva, la emergencia como ciudades con diferentes niveles de complejidad funcional, social y económica de determinados espacios desde la perspectiva de la consideración de la actividad turística como factor catalizador de su crecimiento urbano, pero también teniendo en cuenta las características endógenas y la identidad de las comunidades locales donde se localiza. A los efectos de contextualizar esta cuestión desde la perspectiva latinoamericana, en este apartado se realiza una revisión de los antecedentes de la urbanización turística y la atracción de residentes hacia destinos turísticos tanto a nivel global como, específicamente, en Latinoamérica.

\subsection{Turismo, urbanización turística y atracción de residentes}

Siguiendo el trabajo de Gladstone (1998), se puede decir que el intenso crecimiento de la actividad turística desde mediados del siglo XX a nivel global ha tenido un gran número de consecuencias, siendo una de las más significativas el desarrollo de áreas urbanas asociadas a la afluencia de flujos turísticos. Tal como apunta el Équipe MIT (2008) el turismo ha creado estructuras urbanas específicas inéditas hasta su reciente eclosión, tales como, entre otras, las ciudades turísticas de los espacios litorales. A este fenómeno Mullins (1991; 1992) lo denominó, a partir del estudio de un tramo de la costa australiana, "urbanización turística". Este es, de hecho, el concepto que se utiliza en este artículo a los efectos de caracterizar los procesos de atracción de flujos de residentes, de capital, de información y de conocimiento asociados a la atracción de turistas en los destinos. Según Mullins (1991) la urbanización turística es el proceso por el cual determinadas ciudades que son construidas específicamente por y para el turismo se transforman en espacios de trabajo y de residencia que, además, en sus fases de configuración, se distinguen del resto de los espacios urbanos por tener, entre otros aspectos y según sus resultados, mayor densidad de viviendas, mayor tasa de crecimiento demográfico, mayor proporción de población vieja y de recién llegados, predominio de parejas como tipología familiar, y un ritmo de creación de puestos de trabajo más alto, aunque también un más alto nivel de desempleo. Seguramente uno de los casos más significativos, conocidos y estudiados al respecto es el de la Gold Coast australiana (Bosman et al. 2016).

Varios autores, entre ellos Essex y Brown (1997), Williams y Hall (2000), Gu y Wall (2007), González Reverté (2008), y Holderbaun y Lemos (2012), han profundizado en este concepto a partir del análisis de los procesos ocurridos en otros espacios. González Reverté (2008), por ejemplo, afirma que con este proceso ciertas áreas costeras que poseen un especial atractivo, determinadas condiciones de accesibilidad y que se encuentran en el contexto de ámbitos regionales con cabeceras metropolitanas (como es el caso del litoral que es objeto de análisis en este artículo), adquieren a través del desarrollo del turismo, formas y funciones urbanas que provocan procesos de atracción residencial de carácter permanente. Más en particular, identifica las siguientes características demográficas distintivas de tales ciudades para el caso del mediterráneo español: una mayor capacidad de 
atracción de nuevos residentes y de extranjeros; una disminución en la tasa de envejecimiento y de dependencia debido a las llegadas de jóvenes en edad laboral que compensan los elevados porcentajes de residentes mayores de 65 años; un mayor crecimiento demográfico, de concentración de la riqueza y de la producción; y por último, niveles de cambio social y de formas de convivencia más intensos.

En relación a esta cuestión, Williams y Hall (2000) realizan, por su parte, un aporte interesante cuando caracterizan las formas de movilidad contemporánea hacia los espacios turísticos e identifican algunas situaciones específicas resultado de la relación entre turismo y migraciones. Desde su punto de vista y con el fin de entender la atracción de residentes que provoca el turismo, indican que existen fundamentalmente relaciones entre turismo y trabajo migratorio, entre turismo y migración emprendedora y entre turismo y migración de la tercera edad que establecen una jerarquía de trabajadores migrantes y de nuevos residentes. En la cúspide se encuentran los puestos directivos; a un nivel intermedio se identifican puestos de trabajo calificado ocupado a menudo por migrantes de los mismos lugares de origen de los turistas y a un tercer nivel se encuentra la mano de obra no calificada. Por su parte, la migración de tercera edad se diferencia de las otras migraciones por tratarse de un grupo de edad que no depende de las oportunidades de empleo y de las estructuras económicas locales. Se trata de población que suele disponer de una elevada renta y una mayor disponibilidad de tiempo de ocio.

Un aspecto importante a tener en cuenta en este proceso se relaciona, además, con el efecto que tiene el turismo sobre la industria de la construcción. En esta línea es conocido, tal como apuntan Hollderbaun y Lemos (2012) que el crecimiento turístico, especialmente en el litoral, ocasiona un gran incremento de construcción privada y pública que conlleva a su vez un incremento adicional de puestos de trabajo, que aumenta la intensidad de corriente migratoria (Gu y Wall, 2007), la edificación de nuevas viviendas y unidades habitacionales para nuevos residentes permanentes y, en consecuencia, una muy importante eclosión urbana.

Otros estudios ponen de manifiesto, siguiendo el esquema de Williams y Hall (2000), la capacidad de los destinos turísticos de atraer emprendedores. Se ha analizado, en este sentido, cómo los destinos turísticos atraen a grupos de personas que buscan estilos de vida relacionados con la imagen que se desprende de ellos. Anton Clavé (1997) observó ya a finales del siglo XX para el caso de las localidades del litoral meridional de Cataluña, que las turísticas eran las que tenían un mayor índice de pequeños empresarios. Adicionalmente, en un artículo reciente (Olano et al., 2017) se analiza también para el caso catalán, cómo los destinos turísticos tienen mayor capacidad de la esperada, teniendo en cuenta sus dimensiones demográficas y productivas, de atraer trabajadores profesionales y creativos.

Desde la perspectiva de la estructura del destino, algunos aspectos colaterales a considerar derivado de las dinámicas migratorias que generan los procesos de atracción turística hacia destinos litorales son, en primer lugar, el relacionado con la transformación de viviendas secundarias en residencias para la población permanente (Rovira-Soto y Anton Clavé, 2017, 2018). Otro efecto posible derivado de la existencia de una concentración importante de viviendas de uso temporal es que permite ofrecer alquileres económicos fuera de la temporada turística y facilita el desarrollo de nuevas actividades, como, por ejemplo, la atracción de estudiantes en los casos en los que el destino brinde oferta educativa, o el asentamiento de población con pocos recursos, a menudo en grupos familiares o residenciales con elevado número de personas, en una misma unidad habitacional que migra de los grandes centros 
urbanos hacia los destinos con la finalidad de aprovechar las oportunidades laborales que ofrecen ya sea en ocupaciones directamente relacionadas con el turismo o en otras como la construcción o incluso en sectores informales. Ésta dinámica, genera, por otra parte, procesos de dualidad funcional y residencial en los destinos (De Rivera et al., 2015).

En términos generales, las dinámicas descritas pueden presentar variaciones según la trayectoria del destino, el contexto geográfico en el que se localiza y el nivel y la intensidad de desarrollo de otras actividades productivas. En este sentido, Antón Clavé (Antón Clavé, 2012:5) menciona, por ejemplo, que algunos destinos consolidados pueden llegar a transformarse en espacios urbanos convencionales donde el turismo se configura como el punto de partida de nuevas oportunidades económicas a escala local y regional. Bajo esta óptica, el mismo autor afirma que tales destinos - que denomina transitivos - "han ido evolucionando a partir su uso vacacional principal - con cierta exclusividad - hacia estructuras territoriales que revelan nuevas y múltiples funciones en términos de localización residencial, conectividad, función productiva, capacidad innovadora y aportación a la competitividad territorial de la estructura regional en la que se integran". Esta idea ha sido también desarrollada por Clivaz et al . (2014) cuando examina la conversión, metamorfosis según sus palabras, de destinos en espacios urbanos complejos y multifuncionales así como el desarrollo de su capital social. Un aporte complementario en este mismo sentido es el que realiza González Reverté et al. (2014), cuando se menciona que en los destinos turísticos se pueden producir dinámicas de desarrollo que pueden ir más allá de las basadas en la mera especialización funcional turística, de manera que son capaces de estimular nueva actividad económica e incidir sobre la estructura urbana.

Todo esto conlleva a reconocer que, en contraste notable con otros enfoques que se centran sólo en el análisis de la evolución de la demanda y de la reconversión de la oferta de los destinos, el análisis de los procesos de urbanización turística permite entender cómo evolucionan los destinos a través de procesos dinámicos, incluyendo la necesaria movilidad de personas (no únicamente los turistas), de capitales, de bienes y de información tal como se sostiene, por otra parte, desde los enfoques de la Geografía Económica Evolutiva (Brouder et al., 2017; Sanz Ibáñez y Anton Clavé, 2014).

\subsection{Ciudades creadas por y para el turismo en América Latina}

Es común señalar que, desde la década de los sesenta, el turismo internacional ha sido percibido en América Latina como una estrategia de desarrollo en la medida que aporta divisas y empleo. Tal como lo menciona Fernández Miranda (2015), en el importante período de crecimiento de la economía mundial que va desde 1945 a 1973, además de la expansión del turismo en el mediterráneo, aunque con volúmenes más modestos que los europeos o los norteamericanos, se multiplican las inversiones y empiezan a crecer los desplazamientos de turistas internacionales, regionales y transcontinentales hacia América Latina, primero hacia las playas y posteriormente hacia todo tipo de espacios. Tales flujos se intensifican a partir de la consolidación de las diferentes reformas neoliberales paralelas al nuevo contexto de consumo turístico a nivel mundial de finales del siglo XX. En efecto, la apertura de las economías, la liberalización del comercio y del transporte y las políticas de atracción de inversiones, han acelerado la expansión del turismo en Latinoamérica. Con efectos, externalidades e impactos múltiples tanto positivos como negativos de este proceso, el turismo se 
convierte en un factor explicativo de la transformación de las sociedades latinoamericanas a lo largo del continente durante el último medio siglo (Blázquez y Cañada, 2011).

Uno de los efectos del crecimiento turístico es el que centra el interés de este artículo, es decir, el proceso de urbanización turística asociado al crecimiento demográfico que genera la actividad allí dónde se localiza, con el consiguiente aumento de oportunidades laborales así como la localización de nuevos residentes. Este es un proceso que se puede observar históricamente en algunos destinos característicos de América Latina. Este es el caso, por ejemplo, en México, de Acapulco y Cancún, en Brasil, de Florianópolis Natal y Pipa y en Argentina, de Mar del Plata, Miramar y Villa Gesell.

La valorización de Acapulco, ya a principios del siglo XX, como destino turístico ha significado la transformación de su espacio y la modificación de su organización socioeconómica (Valdivieso y Coll-Hurtado, 2010) debido a los efectos en cadena que ocasionaron la migración y el crecimiento urbano. Así, en una década la población casi se triplicó, porque pasó de 9.993 habitantes en 1940, a 28.512 para 1950, y en 1960 casi se duplicó respecto a la década anterior con 49.149 personas. El incremento de población fue resultado de la idealización de Acapulco en el imaginario de los migrantes para conseguir un mejor trabajo y, consecuentemente, mejorar su calidad de vida. Es importante señalar, sin embargo, desde la perspectiva de las características de los procesos urbanos resultantes, que debido a que la mayoría de las personas llegadas a la ciudad tenían un nivel adquisitivo bajo, la cuestión del acceso a la vivienda se convirtió rápidamente en un problema principal. Además, se consolidó una clara división territorial entre lo turístico y lo residencial que ha acompañado la expansión a través del tiempo.

También en México, el turismo convirtió a Cancún en la ciudad con mayor dinamismo urbano como consecuencia de la llegada de nuevos residentes (Anaya y Palafox, 2007; Lozano y Ramírez, 2007; Calderón y Orozco, 2009; Boggio Vázquez, 2008). Además, su consolidación ha abierto nuevos espacios a los procesos de urbanización en los alrededores inmediatos, generando el surgimiento de Playa del Carmen y lo que se conoce como Rivera Maya. En este sentido, Mendoza y Leal (2010), afirman que Rivera Maya ha experimentado un ritmo de crecimiento muy explosivo, incluso mucho mayor que el de Cancún, de manera que actualmente esta zona registra el mayor crecimiento demográfico de América Latina y el más alto porcentaje de inmigración de todo México.

El crecimiento demográfico y urbano producto de la actividad turística también es claramente observable en algunas ciudades de Brasil. Es el caso de Florianópolis, que presenta el mayor desarrollo turístico del sur de Brasil siendo hoy considerada asimismo la capital de estado con mayor calidad de vida de Brasil y la cuarta mejor ciudad para vivir en el país, aunque presente asimismo problemas de degradación ambiental, rebasamiento de la capacidad de carga social y falta de infraestructura que condicionan la sostenibilidad de esta dinámica (Soares y Gandara, 2010). En el nordeste brasilero, en Natal y Pipa, también se evidencia la capacidad de catalización del crecimiento urbano y transformación social que tiene el turismo con la atracción de nuevos residentes a los destinos y claros procesos de segregación espacial entre ellos y los turistas. Dicha segregación se manifiesta, además, a través de dinámicas de refuncionalización del espacio, producción inmobiliaria, privatización del espacio público y degradación socioespacial (Fonseca y Costa, 2004).

En Argentina pueden observarse asimismo dinámicas de urbanización turísticas relevantes. De hecho, tal como lo definen Campodónico y da Cunha (2009) existe una relación 
muy importante entre los orígenes del turismo argentino y el proceso de urbanización general del país ya desde las primeras tres décadas del siglo XX. Más en concreto, siguiendo a Bouvet et al. (2005), se puede decir que en poco más de 110 años ha surgido un conjunto significativo de ciudades balneario (Bertoncello, 1992) más allá de los ya conocidos destinos como Mar del Plata, que además de aglutinar a más de un millón de turistas durante la estación estival (Benseny, 2011; Mantero, 1997) durante las décadas de los ochenta y noventa se ha caracterizado por un proceso de transformación en el que ha cambiado el foco desde el turismo a la calidad de vida de los residentes.

En este punto, es importante destacar, que siendo Mar del Plata el destino emblemático del litoral bonaerense, varios autores (Bertoncello, 1992; Mantero, 1997; Zulaica y Celemín, 2008; Campodónico y da Cunha, 2009; Benseny, 2011; entre otros) han analizado el proceso de evolución y desarrollo del destino turístico. Un caso interesante de mencionar, es el que realizan Almeida-García y Balbuena Vázquez (2014) al desarrollar un estudio comparado entre Mar del Plata y Málaga (España) por sus similitudes en su historia turística, tamaño demográfico y función territorial. Así, concluyen que tanto en la Costa bonaerense como en la Costa del Sol responden a pautas explicadas por modelos turísticourbanísticos y por los procesos de expansión de tejido urbano en las áreas metropolitanas, sumado a las estrechas relaciones entre negocio inmobiliario y segunda residencia.

Por otro lado, Almeida-García y Balbuena Vázquez (2014: 336) manifiestan que “... un elemento esencial para entender el funcionamiento de Mar del Plata es la situación de la demanda turística nacional. La escasez de oferta de estaciones balnearias, la cercanía a los trece millones de habitantes del área metropolitana de Buenos Aires, la imagen turística consolidada de Mar del Plata dentro del país y otros factores de orden político y económico (dificultades de cambio de divisas, etc.), son hechos que hace que buena parte de la demanda sea "cautiva". Esto provoca que independientemente de la obsolescencia del destino, la demanda se mantenga con lo que se dificulta la creación de estrategias de reconversión..."

En cualquier caso, paralelamente a los procesos experimentados en Mar del Plata surgen otros balnearios en la costa bonaerense, como Santa Clara del Mar, donde el impulso del turismo en las últimas décadas ha promovido la expansión urbanística (Padilla y Benseny, 2014). De forma diferente pero bajo la misma dinámica urbanizadora, en otros destinos del litoral argentino (como Miramar y Villa Gesell) con dinámicas de desarrollo espontáneo debido a la ausencia de un plan ordenador del uso del suelo, prevalecen las urbanizaciones turísticas fraccionadas, con ocupación dispersa y uso estacional. Además, se observa en todos ellos la atracción de trabajadores y de emprendedores para la construcción, el pequeño comercio y la prestación de servicios, sumada a los flujos migratorios (Mantero, 2002; Merlotto, 2010).

\section{METODOLOGÍA}

\section{1. Área geográfica de estudio}

La provincia de Buenos Aires es la más extensa de Argentina con una superficie de $304.907 \mathrm{~km}^{2}$ y 15.625.084 habitantes según el censo de Población, Hogares y Viviendas 2010. Es también la principal provincia del país en otros varios aspectos: contiene el 
$39 \%$ de la población, el $33 \%$ de las exportaciones, el $37 \%$ del producto y más del $50 \%$ de la industria. Política y administrativamente se encuentra dividida en 135 municipios, todos con las mismas atribuciones y potestades, pero que presentan una gran diversidad en términos geográficos, sociales y económicos.

Existen varios estudios, entre ellos el de Quesada Aramburu y Cadelli (2012), que dividen la provincia en regiones homogéneas desde el punto de vista productivo y geográfico y que consideran una de ellas la región costera vinculada al turismo. En esta región se ha producido una acción transformadora del territorio a través de la valorización turística de los recursos naturales y la urbanización del litoral. Así, además del desarrollo turístico de Mar del Plata y la valorización del borde costero con las grandes estancias con fines inmobiliarios, han aparecido diferentes balnearios y se ha consolidado un sistema de asentamientos sobre el territorio litoral caracterizado por el desarrollo de ciudades turísticas en tierras improductivas para la actividad agrícola-ganadera (principal actividad económica de la provincia).

Las unidades de análisis que se utilizan en este trabajo son ciudades que según el Censo Nacional de Población, Hogares y Viviendas realizado por INDEC 2001, poseen una población igual o superior a 2000 habitantes y que integran los Municipios Costeros de la Provincia de Buenos Aires - MCBA- (Figura 1).

\section{Figura 1 \\ LOCALIZACIÓN DE LAS UNIDADES DE ANÁLISIS}

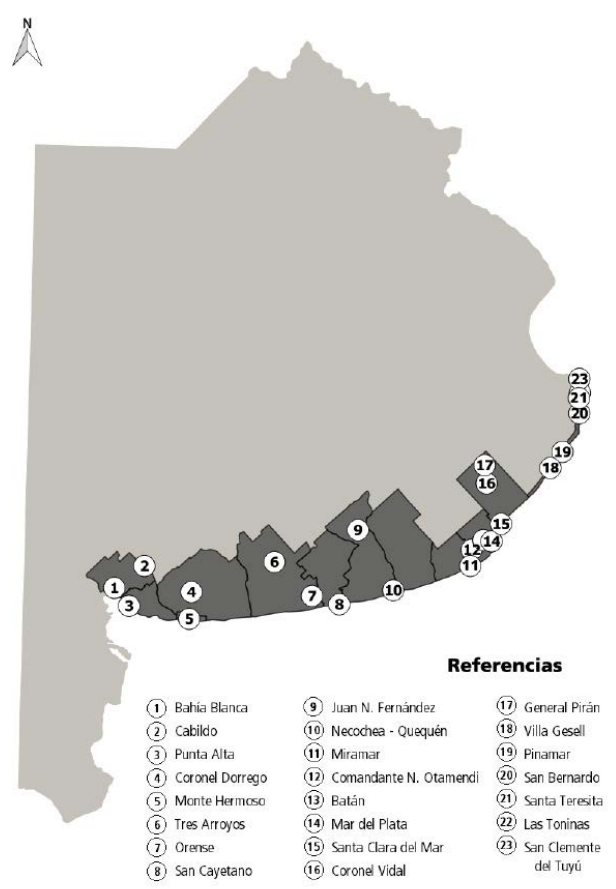

Fuente: Elaboración propia. 


\subsection{Técnica de análisis y variables utilizadas}

Puesto que el objetivo de este estudio es identificar la existencia de diferentes dinámicas urbanas derivadas del papel del turismo en el desarrollo de los municipios litorales de la provincia de Buenos Aires se propone el estudio de la evolución de diversas variables demográficas y económicas durante el periodo 2001 - 2010 y la agrupación de las ciudades en diferentes conglomerados a través de técnicas estadísticas de clasificación que permitan agruparlas en grupos relativamente homogéneos. Para ello se realiza un análisis de conglomerados.

El análisis de conglomerados o análisis de clusters es una técnica multivariante eminentemente exploratoria de datos que sirve, entre otras cuestiones, para resolver problemas de clasificación (Quesada Aramburú y Cadelli, 2012). La aplicación de la técnica de análisis de conglomerados permite agrupar distintas unidades en grupos relativamente homogéneos llamados clusters, considerando simultáneamente indicadores de distinto tipo. Los elementos de cada grupo tienden a ser similares entre sí (alta homogeneidad interna dentro del clúster) y diferentes a los elementos de otros grupos (alta heterogeneidad externa entre clusters) con respecto a algún criterio de selección determinado. En este trabajo, se aplica la técnica para tipificar las ciudades que comprenden a los municipios costeros de la provincia de Buenos Aires a partir de su condición turística y del análisis del impacto de tal condición en el crecimiento urbano.

A grandes rasgos, la identificación de clusters se realiza a través de un procedimiento en tres fases. El primer paso consiste en la selección de las variables en las que se basará el agrupamiento. Según Ferrán Aranaz (1996), esta selección debe realizarse atendiendo tanto a cuestiones teóricas como prácticas, es decir, debe basarse tanto en la revisión de la literatura sobre el tema como en investigaciones pasadas. Asimismo, las variables deben poder describir la similitud entre las unidades a comparar en términos relevantes para la investigación en curso, evitándose, por otra parte, la inclusión de variables redundantes ya que pueden distorsionar la solución al problema de agrupación. Las variables que se han escogido para fundamentar la expansión urbana de las ciudades turísticas, en base a la discusión teórica planteada y a las necesidades de comprobación de hipótesis, son las siguientes (Tabla 1).

\section{Tabla 1 \\ DEFINICIÓN DE LAS VARIABLES}

\begin{tabular}{|l|l|}
\hline \multicolumn{1}{|c|}{ Variable } & \multicolumn{1}{|c|}{ Descripción } \\
\hline Localización en la Costa (LC) & $\begin{array}{l}\text { Mide la existencia del recurso que puede presentar un } \\
\text { potencial atractivo turístico pero que aún no lo es. Si tiene } \\
\text { presencia vale 1, sino 0. }\end{array}$ \\
\hline Uso Turístico de la Playa (UTP) & $\begin{array}{l}\text { Se considera cuando la playa es un atractivo del destino } \\
\text { turístico. Si es un atractivo vale 1, sino 0. }\end{array}$ \\
\hline Tasa de Función Turística (TFT) & $\begin{array}{l}\text { Es la proporción de plazas turísticas (viviendas de potencial } \\
\text { uso turístico + hoteleras) respecto a la población total de cada } \\
\text { localidad. }\end{array}$ \\
\hline Variación poblacional (VP) & $\begin{array}{l}\text { Es la variación de la población en porcentaje del año 2010 } \\
\text { respecto al año 2001, y del año 2001 respecto al año 1991. }\end{array}$ \\
\hline
\end{tabular}




\begin{tabular}{|l|l|}
\hline \multicolumn{1}{|c|}{ Variable } & \multicolumn{1}{|c|}{ Descripción } \\
\hline Índice de envejecimiento (IE) & $\begin{array}{l}\text { Es la relación entre la cantidad de personas adultas mayores } \\
\text { y la cantidad de menores de 15 años. Se calcula como el } \\
\text { cociente entre las personas de 65 años respecto a aquellas } \\
\text { menores de 15 (en porcentaje). }\end{array}$ \\
\hline Índice de actividad (IA) & $\begin{array}{l}\text { Analiza la relación entre la población activa respecto a la } \\
\text { población inactiva. }\end{array}$ \\
\hline Índice de ocupación (IO) & $\begin{array}{l}\text { Mide la relación entre ocupados y activos, representando } \\
\text { el número de población que efectivamente se encuentra } \\
\text { trabajando. }\end{array}$ \\
\hline Índice de hacinamiento (IH) & $\begin{array}{l}\text { Mide la calidad habitacional de los hogares a partir de un } \\
\text { indicador promedio que calcula la cantidad de habitantes } \\
\text { que se encuentran en una vivienda desde 0,50 a más de 3 } \\
\text { personas por cuarto. El resultado indica la cantidad promedio } \\
\text { de personas por habitación en los hogares de cada localidad }\end{array}$ \\
\hline
\end{tabular}

Fuente: Elaboración propia.

Es de interés indicar, respecto al Índice de Actividad y al Índice de Ocupación que debe tenerse en cuenta que son valores que se determinan a partir de datos censales que se encuentran influenciados por la coyuntura existente en el momento de realizar el censo. Desde el punto de vista técnico, se debe tener en cuenta que los datos fueron obtenidos en temporada baja razón por la cual es probable que no se alcance a reflejar todo el efecto del turismo en el mercado laboral de estas ciudades. Desde una perspectiva económica, es importante indicar que el estado general de la economía del país puede influir en las evidencias obtenidas para cada Censo. De hecho, en el año 2001, Argentina se encontraba en recesión con altas tasas de desempleo que desembocaron en la profunda crisis del 2002. Sin embargo, durante el 2010, el país presentaba un momento de crecimiento económico, con un alto nivel de empleo y actividad.

Una vez seleccionadas las variables, un segundo paso del análisis consiste en definir la medida de "similitud" o "equivalencia" que se empleará para comparar a las unidades entre sí. La estrategia más usual consiste en usar alguna definición de distancia. Según Ferrán Aranaz (1996), si bien existen muchas medidas de distancia, la más utilizada es la distancia euclídea al cuadrado, especialmente recomendada para el método de Ward. Dado que muchas de las medidas de distancia son sensibles a diferencias de escala entre variables, se ha trabajado con datos estandarizados (Quesada Aramburú y Cadelli, 2012).

El último paso consiste en la selección del procedimiento de agrupación a utilizar, para lo cual se dispone de dos tipos de métodos: jerárquicos y no jerárquicos. Los procedimientos jerárquicos se caracterizan por el desarrollo de una estructura en forma de árbol que puede obtenerse por aglomeración (se empieza con cada objeto formando un conjunto separado y se va agrupando con otras unidades similares en aglomerados cada vez más grandes hasta llegar a un solo grupo) o por división (inicialmente todos los objetos están agrupados en un único conjunto que se va dividiendo hasta que cada objeto o unidad es un grupo independiente). La selección del número óptimo de grupos queda a criterio del investigador ya que no existe un proceso objetivo de selección. En la práctica suelen 
calcularse distintas soluciones de aglomeración para luego optar por una de ellas en base al sentido común, a fundamentos teóricos, o a un criterio fijado de antemano. Por otro lado, en los procedimientos no jerárquicos, generalmente conocidos como agrupación de $\mathrm{K}$ medias, los objetos son agrupados en torno a determinados puntos llamados centros o semillas existiendo dos variantes principales. La primera, es básicamente una técnica de clasificación que consiste en seleccionar los centros previamente y agrupar los datos más cercanos en torno a ellos de acuerdo a algún método (umbral secuencial, umbral paralelo, división para la optimización). En la segunda variante, la técnica se utiliza de manera exploratoria ya que se comienza seleccionando los K casos más distantes entre sí y luego se procede a agrupar los datos al centro más próximo, actualizando el valor de los centros a medida que se van incorporando nuevos casos. Tal como sucede con los procedimientos jerárquicos, tampoco existe en este caso un proceso objetivo de determinación del número de clusters o grupos. Los procedimientos no jerárquicos tienen dos desventajas importantes respecto a los jerárquicos, en concreto, que el número de grupos a conformar debe especificarse previamente y que la selección de los centros de los aglomerados es arbitraria, pudiendo conducir a que los resultados del conglomerado dependan del orden de las observaciones en la base de datos. Pese a ello, son ampliamente utilizados porque permiten trabajar con una mayor cantidad de datos que los jerárquicos $\mathrm{y}$, fundamentalmente, porque estos últimos no pueden recuperarse de decisiones incorrectas en las etapas previas del proceso de aglomeración.

Para este trabajo se ha decidido combinar ambos tipos de procedimientos para explotar las ventajas y tratar de minimizar las desventajas asociadas a cada uno de ellos. Así, primero se ha utilizado un procedimiento jerárquico de manera exploratoria a fin de determinar el número de clusters a conformar y a su vez generar valores de referencia que sirvieran de semillas o puntos de partida de la aglomeración no jerárquica. Luego, utilizando como insumos la cantidad de grupos obtenidos mediante el método jerárquico, se ha procedido a clasificar a las ciudades empleando el procedimiento de agrupación de K-medias. Este procedimiento se realiza en función de una base de datos que se diseña a partir de del Censo de Población, Hogares y Viviendas 2001 -2010, elaborado por INDEC. Para realizar los grupos se ha empleado el programa estadístico informático SPSS.

\section{RESULTADOS}

\subsection{Análisis del comportamiento demográfico de las ciudades a partir de su condi- ción turística según datos 2001}

Para analizar la evolución de las ciudades costeras de la provincia de Buenos Aires se consideran dos periodos que coinciden con los Censos de Población y Vivienda del Instituto Nacional de Estadísticas y Censos de la República Argentina de los años 2001 y 2010 (Tabla 2). 
DINÁMICAS DE URBANIZACIÓN TURÍSTICA EN EL LITORAL DE BUENOS AIRES, ARGENTINA 115

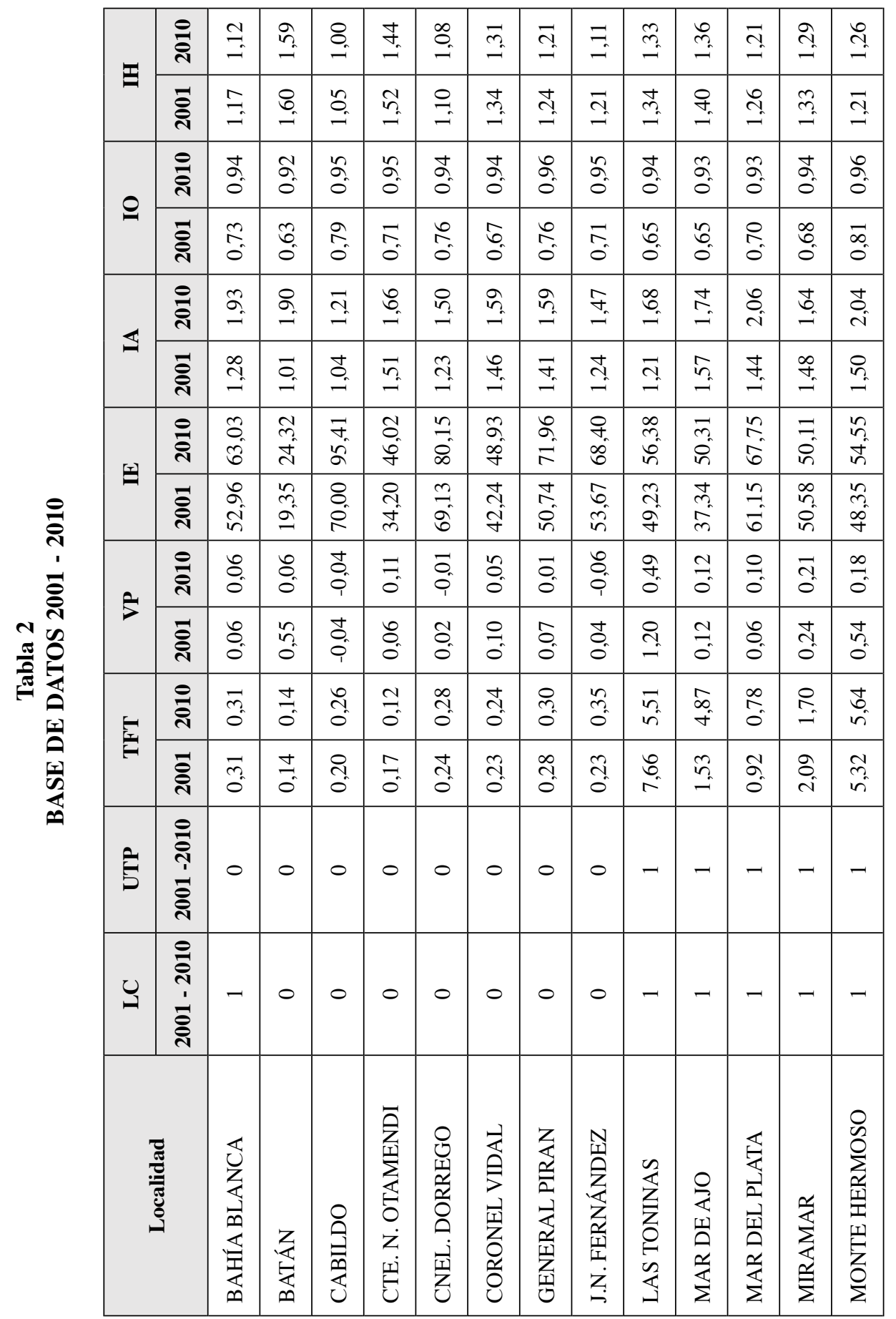




\begin{tabular}{|c|c|c|c|c|c|c|c|c|c|c|c|}
\hline \multirow{2}{*}{ 四 } & 을 & $\Xi$ & $\cong$ & $\vec{F}$ & 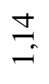 & $\stackrel{0}{=}$ & กิ & $\stackrel{\text { తn }}{-}$ & $\vec{m}$ & $\exists$ & ले \\
\hline & $\overline{\mathrm{d}}$ & $\cong$ & $\stackrel{8}{-}$ & r & $\stackrel{0}{=}$ & $\cong$ & กี & ปี & 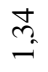 & $\stackrel{\infty}{0}$ & $\hat{n}$ \\
\hline \multirow{2}{*}{$\stackrel{\varrho}{0}$} & $\stackrel{\bar{\Xi}}{\bar{乛}}$ & $\stackrel{+}{\sigma}$ & $\hat{\sigma}$ & $\stackrel{\Delta}{\sigma}$ & $\hat{\sigma}$ & ஃ. & ठ̊. & ふু & $\stackrel{\Delta}{\sigma}$ & $\stackrel{\mathscr{a}}{0}$ & $\begin{array}{l}\dot{\sigma} \\
\text {. }\end{array}$ \\
\hline & 亏్亏 & $\frac{N}{0}$ & $\begin{array}{l}0 \\
\infty \\
0\end{array}$ & $\begin{array}{l}\infty \\
0 \\
0\end{array}$ & $\begin{array}{l}\infty \\
0 \\
0\end{array}$ & $\frac{2}{0}$ & $\underset{0}{\stackrel{N}{0}}$ & $\overbrace{0}^{8}$ & $\begin{array}{l}0 \\
0\end{array}$ & $\stackrel{\hat{\sigma}}{0}$ & $\frac{0}{0}$ \\
\hline \multirow{2}{*}{ 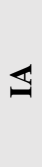 } & 을 & $\infty$ & $\approx$ & $\begin{array}{l}\text { ते } \\
\text { in }\end{array}$ & $\cong$ & in & $\cong$ & $\underset{-}{\mathbb{O}}$ & $\underset{\sigma}{\sigma}$ & $\stackrel{\Delta}{\sigma}$ & $\bar{\sigma}$ \\
\hline & 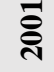 & $\stackrel{\overbrace{}}{2}$ & $\stackrel{n}{\sim}$ & 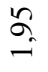 & $\Xi$ & $\bar{n}$ & $\stackrel{\infty}{?}$ & $\stackrel{2}{2}$ & ㄱ. & 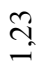 & $\stackrel{\infty}{0}$ \\
\hline \multirow{2}{*}{ 들 } & 을 & 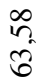 & $\begin{array}{l}\stackrel{2}{2} \\
\infty\end{array}$ & $\frac{}{\ddot{n}}$ & $\begin{array}{l}\tilde{b} \\
i\end{array}$ & $\frac{\infty}{\pi}$ & $\begin{array}{l}+ \\
\infty \\
\wp^{\circ}\end{array}$ & $\hat{\sigma}$ & $\begin{array}{l}\hat{m} \\
\infty \\
n\end{array}$ & $\underset{\sim}{\sigma}$ & $\begin{array}{l}\stackrel{2}{2} \\
\infty \\
\infty \\
\infty\end{array}$ \\
\hline & స్తి & $\begin{array}{l}\hat{n} \\
\stackrel{n}{n}\end{array}$ & $\begin{array}{l}\text { ले } \\
\text { in. } \\
\text { in }\end{array}$ & $\begin{array}{l}\text { ठ઼. } \\
\text { নे }\end{array}$ & $\begin{array}{l}\infty \\
\text { ले }\end{array}$ & $\begin{array}{l}\bar{n} \\
\text { nn }\end{array}$ & $\begin{array}{l} \pm \\
\dot{f}\end{array}$ & $\begin{array}{l}0 \\
\infty \\
\infty \\
n\end{array}$ & $\begin{array}{l}\infty \\
\text { r. } \\
\underbrace{}_{0}\end{array}$ & $\begin{array}{l}\text { q } \\
8\end{array}$ & $\begin{array}{l}\tilde{n} \\
\dot{n}\end{array}$ \\
\hline \multirow{2}{*}{$\vec{p}$} & 을 & $\begin{array}{l}\circ \\
\stackrel{0}{0}\end{array}$ & $\begin{array}{l}n \\
0 \\
0 \\
1\end{array}$ & $\stackrel{\text { }}{0}$ & 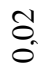 & $\stackrel{0}{0}$ & $\stackrel{8}{0}$ & $\stackrel{\infty}{+}$ & $\frac{\infty}{0}$ & $\stackrel{1}{0}$ & त̂ \\
\hline & స్తి & $\begin{array}{l}8 \\
\text { o. }\end{array}$ & $\begin{array}{l}\overrightarrow{0} \\
0 \\
0\end{array}$ & $\underset{\sigma}{\sigma}$ & $\stackrel{\sigma}{0}$ & $\frac{0}{0}$ & ơ & $\frac{t}{0}$ & $\begin{array}{l}\infty \\
\ddot{0} \\
0\end{array}$ & 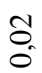 & $\begin{array}{l}\text { ñ } \\
\text { o. }\end{array}$ \\
\hline \multirow{2}{*}{ 穿 } & $\stackrel{ }{\overline{\tilde{N}}}$ & ñ & $\stackrel{n}{n}$ & $\begin{array}{l}\infty \\
\stackrel{\infty}{1} \\
\stackrel{1}{1}\end{array}$ & $\begin{array}{c}\tilde{\sigma} \\
\tilde{0}\end{array}$ & $\stackrel{N}{2}$ & $\begin{array}{l}\text { ర్ } \\
\text { ri }\end{array}$ & $\underset{\dot{O}}{\dot{O}}$ & $\hat{n}$ & $\overbrace{0}^{+}$ & $\begin{array}{l}\hat{0} \\
\dot{m}\end{array}$ \\
\hline & $\overline{\mathscr{\Xi}}$ & ñ & $\underset{+}{ \pm}$ & $\begin{array}{l}\text { กิ } \\
\text { m. }\end{array}$ & ત્ & $\hat{n}$ & $\frac{n}{n}$ & $\hat{r}$ & nे & $\vec{m}_{0}$ & $\begin{array}{l}\text { ñ } \\
\text { r }\end{array}$ \\
\hline 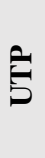 & 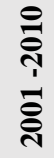 & - & - & - & 0 & 0 & - & - & - & 0 & - \\
\hline בِ & 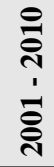 & - & - & - & - & 0 & - & - & - & 0 & - \\
\hline \multicolumn{2}{|c|}{ 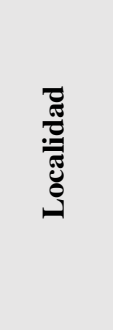 } & 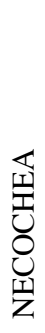 & 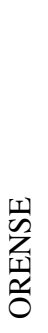 & 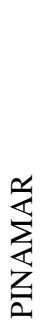 & 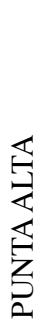 & 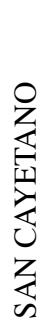 & 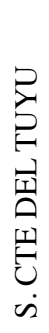 & 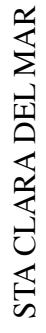 & 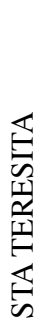 & 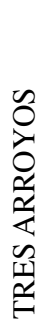 & 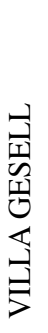 \\
\hline
\end{tabular}


El análisis de los datos de 2001 (Figura 2) permite identificar cinco conglomerados de ciudades. Las ciudades turísticas se encuentran clasificadas en los clústers 3 y 4 , mientras que las no turísticas están en el clúster 1. Además, se pueden visualizar algunos casos específicos, como Batan y Las Toninas que quedan sin agruparse.

\section{Figura 2}

\section{DENDOGRAMA 2001}

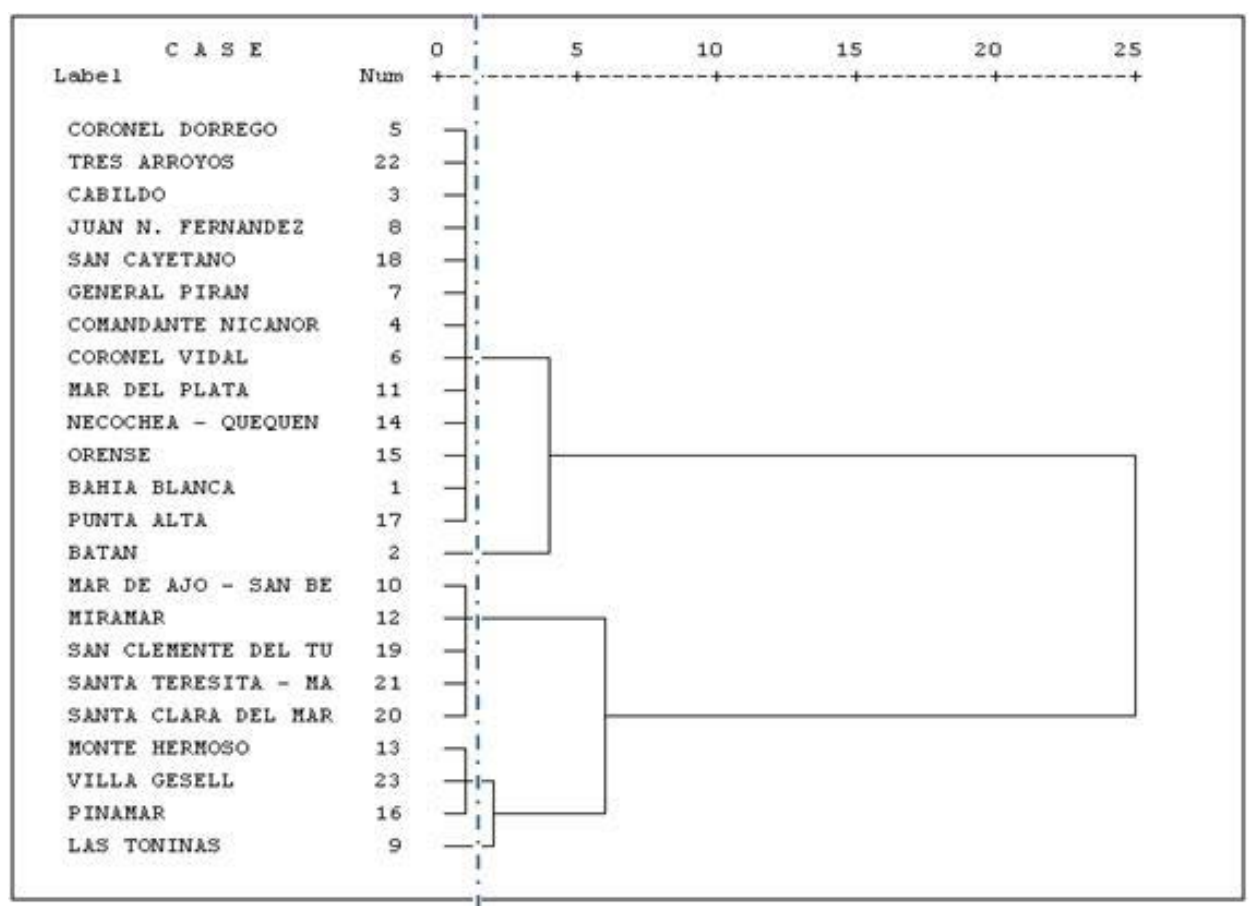

Fuente: Elaboración propia.

Para explicar de manera integral los resultados encontrados se presenta la Tabla 3 donde se muestra para cada agrupamiento resultante el valor promedio de las variables utilizadas. 


\section{Tabla 3 \\ PROMEDIO DE CADA VARIABLE, POR CLÚSTER, SEGÚN DATOS 2001}

\begin{tabular}{|c|l|c|c|c|c|c|c|c|c|}
\hline Clúster & \multicolumn{1}{|c|}{ Ciudades que integran } & LC & UTP & TFT & VP & IE & IA & IO & IH \\
\hline $\mathbf{1}$ & $\begin{array}{l}\text { Dorrego - T. Arroyos - Cabildo - } \\
\text { Fernández -Pirán - San Cayetano } \\
\text { - Nicanor - Vidal - Mar del Plata } \\
\text { - Necochea- Orense -Bahía Blanca } \\
\text { - Punta Alta }\end{array}$ & 0,38 & 0,23 & 0,34 & 0,05 & 54,12 & 1,31 & 0,75 & 1,20 \\
\hline $\mathbf{2}$ & Batán & 0,00 & 0,00 & 0,14 & 0,55 & 19,35 & 1,01 & 0,63 & 1,60 \\
\hline $\mathbf{3}$ & $\begin{array}{l}\text { Mar de Ajo - Miramar - San } \\
\text { Clemente del Tuyú - Santa } \\
\text { Teresita- Santa Clara del Mar }\end{array}$ & 1,00 & 1,00 & 2,95 & 0,44 & 47,46 & 1,41 & 0,67 & 1,32 \\
\hline $\mathbf{4}$ & $\begin{array}{l}\text { Monte Hermoso - Villa Gesell - } \\
\text { Pinamar }\end{array}$ & 1,00 & 1,00 & 4,01 & 0,68 & 37,29 & 1,71 & 0,79 & 1,31 \\
\hline $\mathbf{5}$ & \begin{tabular}{l} 
Las Toninas \\
\hline
\end{tabular} & 1,00 & 1,00 & 7,66 & 1,20 & 49,23 & 1,21 & 0,65 & 1,34 \\
\hline
\end{tabular}

Fuente: Elaboración propia.

Se observa que las variables que presentan una mayor influencia en la conformación de los diferentes conglomerados en 2001 - ya que son los que demuestran una mayor desigualdad entre los valores promedio- son la TFT, la VP y el IE. El resto no presentan grandes diferencias en los valores de promedio obtenidos, por lo que se puede concluir que en 2001 no son aspectos que intervengan decididamente en la definición del clúster, aunque sí pueden explicar algunas características diferenciales que se analizarán más adelante. La TFT representa el papel del factor turístico respecto al no turístico. Así, si los resultados son mayores a 1 se verifica que el turismo es un factor importante en la composición de la ciudad.

Más allá de la clasificación resultante, es necesario realizar algunas consideraciones particulares que permiten profundizar en el análisis. Ello es especialmente relevante para los casos de Mar del Plata y Necochea por una parte y de Las Toninas y Batán, por otra. En relación a las primeras, si bien estas ciudades quedan clasificadas en un clúster no turístico, es conocido que una de sus principales actividades económicas es justamente el turismo. Sin embargo, haciendo referencia a lo especificado en el apartado de antecedentes conceptuales y observando el comportamiento de las variables de VP y TFT en ambas ciudades, se puede entender que se trata de destinos "maduros" que se están transformando desde una perspectiva funcional hacia ciudades con presencia de otros sectores y actividades. Esta consideración justifica esta clasificación. Así, se verifica que la VP presenta 
valores muy bajos, siendo el de Mar del Plata 0,06 y Necochea 0,09, lo cual implica que el crecimiento demográfico durante el período considerado es estable. Por otro lado, la TFT en Mar del Plata alcanza el valor de 0,92 mientras que en Necochea es de 0,55. Finalmente, al observar el IE se deduce que ambas localidades presentan valores más altos que el promedio de las ciudades turísticas.

En cuanto al IA, se puede apreciar que Mar del Plata presenta un valor más alto que el promedio del clúster, lo que puede indicar que es una ciudad que se destaca por su desarrollo económico. Otro dato interesante se relaciona con el IH, ya que tanto Necochea como Mar del Plata, arrojan valores por debajo de la media de los conglomerados turísticos. Esto podría indicar que ambas ciudades, $-\mathrm{y}$ ello es de gran interés desde la perspectiva del análisis para 2001 - , aun teniendo una dinámica turística reconocida, se trata de destinos que han iniciado un proceso de transformación hacia estructuras urbanas convencionales.

El otro caso particular a considerar es el de Las Toninas, que al contrario de los casos anteriores, es un destino emergente que presenta un crecimiento poblacional más que importante alcanzando un valor de 1,20 y una TFT extraordinaria con un valor de 7,66. Presenta el mayor valor en cuanto a variación poblacional, lo que indica un gran aumento demográfico, un IA e IO promedio (que puede estar influenciado por el momento en el que se toma el Censo) y un IH superior al que presentan las localidades no turísticas. Todo ello denota que el turismo es una actividad fundamental para su desarrollo si bien se encuentra en la primera etapa de desarrollo turístico. El último caso a comentar es Batán que además de quedar sola, se trata de la ciudad más joven de la muestra con una VP de 0,55 que indica que ha incrementado su población de manera considerable. Esta situación puede explicarse a partir del análisis de su condición como ciudad de servicios debido a su cercanía a Mar del Plata.

Como conclusión de la conformación de las aglomeraciones para este periodo, se puede decir que a medida que aumenta la TFT — es decir, el papel relativo del turismo en las ciudades - , se observa un aumento del crecimiento poblacional, del índice de actividad y del índice de hacinamiento y, paralelamente, una disminución del índice de envejecimiento.

\subsection{Determinación de conglomerados en 2010 y análisis de su evolución en el tiempo}

A continuación, se explora la situación de las ciudades analizadas en 2010 a los efectos de determinar el papel del turismo en su evolución reciente (Figura 3 y Tabla 4).

La primera evidencia que se obtiene es la reconfiguración de los grupos de ciudades respecto a 2001 con la reubicación de algunas ciudades de manera que se producen cambios dentro de los "no turísticos" y los "turísticos", pero no entre ellos. Así, por ejemplo, Mar de Ajó, se agrupa ahora con las localidades que presentan una mayor influencia del turismo y arrojan el promedio más alto de TFT, poco más de 5 veces mayor la cantidad de turistas que los residentes.

Mar del Plata, por su parte, sigue presentando la particularidad de permanecer en un grupo "no turístico", y se observa además que su TFT ha decrecido durante el último período. Ello implica que el turismo tiene cada vez una menor influencia con respecto a otras actividades. Su crecimiento poblacional (moderado) y los aumentos del IA e IO podrían estar demostrando además que existen otras actividades económicas - distintas al turismo - que están generando desarrollo urbano. 
Figura 3

DENDOGRAMA 2010

\begin{tabular}{|c|c|c|c|c|c|c|c|}
\hline$C \& S E$ & Num & ${ }^{0} i$ & 5 & 10 & 15 & 20 & 25 \\
\hline Labe1 & Num & & & & & & \\
\hline GENERAL PIRAN & 7 & 7i & & & & & \\
\hline SAN CAYETANO & 18 & $-i$ & & & & & \\
\hline JUAN N. FERNANDEZ & 8 & - & & & & & \\
\hline TRES ARROYOS & 22 & $-! !$ & & & & & \\
\hline CABILDO & 3 & - & & & & & \\
\hline CORONEL DORREGO & 5 & -1 & & & & & \\
\hline COHANDANTE NICANOR & 4 & $-i$ & & & & & \\
\hline CORONEL VIDAL & 6 & $-_{i}$ & & & & & \\
\hline MAR DEL PLATA & 11 & $7 i$ & & & & & \\
\hline $\begin{array}{l}\text { NECOCHEA - QUEQUEN } \\
\text { ORENSE }\end{array}$ & $\begin{array}{l}14 \\
15\end{array}$ & -1 & & & & & \\
\hline BAHIA BLANCA & 1 & - ! & & & & & \\
\hline PUNTA ALTA & 17 & \lrcorner$_{1}$ & & & & & \\
\hline BATAN & 2 & - & & & & & \\
\hline SAN CLEMENTE DEL TU & 19 & $\neg i$ & & & & & \\
\hline SANTA TERESITA - MA & 21 & & & & & & \\
\hline MIRAMAR & 12 & - & & & & & \\
\hline SANTA CLARA DEL MAR & 20 & $-!$ & & & & & \\
\hline MAR DE AJO - SAN BE & 10 & $\neg^{\prime}$ & & & & & \\
\hline $\begin{array}{l}\text { MONTE HERMOSO } \\
\text { LAS TONINAS }\end{array}$ & $\begin{array}{r}13 \\
9\end{array}$ & Ji & & & & & \\
\hline PINAHAR & 16 & & & & & & \\
\hline VILLA GESELL & 23 & & & & & & \\
\hline
\end{tabular}

Fuente: Elaboración propia.

Tabla 4

PROMEDIO DE CADA VARIABLE, POR CLÚSTER, SEGÚN DATOS 2010

\begin{tabular}{|c|l|c|c|c|c|c|c|c|c|}
\hline Clúster & \multicolumn{1}{|c}{ Ciudades que integran } & LC & UTP & TFT & VP & IE & IA & IO & IH \\
\hline $\mathbf{1}$ & $\begin{array}{l}\text { Dorrego - Tres Arroyos - Cabildo } \\
- \text { Fernández - Pirán - S. Cayetano } \\
\text { - Nicanor - Vidal }\end{array}$ & 0,00 & 0,00 & 0,28 & 0,02 & 69,39 & 1,57 & 0,95 & 1,18 \\
\hline $\mathbf{2}$ & $\begin{array}{l}\text { M. del Plata - Necochea - Orense } \\
\text { - B. Blanca - P. Alta }\end{array}$ & 1,00 & 0,60 & 0,48 & 0,04 & 61,75 & 1,86 & 0,94 & 1,15 \\
\hline $\mathbf{3}$ & Batán & 0,00 & 0,00 & 0,14 & 0,06 & 24,32 & 1,90 & 0,92 & 1,59 \\
\hline $\mathbf{4}$ & $\begin{array}{l}\text { Miramar - San Clemente del Tuyú } \\
- \text { Santa Teresita - Santa Clara del } \\
\text { Mar }\end{array}$ & 1,00 & 1,00 & 3,23 & 0,24 & 58,32 & 1,66 & 0,94 & 1,28 \\
\hline $\mathbf{5}$ & $\begin{array}{l}\text { Mar de Ajo - Monte Hermoso -- } \\
\text { Las Toninas }\end{array}$ & 1,00 & 1,00 & 5,34 & 0,26 & 53,75 & 1,82 & 0,94 & 1,32 \\
\hline $\mathbf{6}$ & Villa Gesell - Pinamar & 1,00 & 1,00 & 3,08 & 0,25 & 36,93 & 2,09 & 0,94 & 1,40 \\
\hline
\end{tabular}

Fuente: Elaboración propia. 
Del mismo modo, se observa que las otras ciudades que conforman este conglomerado son ciudades con un desarrollo importante. Tal es el caso de Bahía Blanca que cuenta con un puerto y polo industrial; Necochea que además de ser un destino turístico, presenta una importante actividad cerealera, pesquera y portuaria; y Punta Alta, ciudad en la que se asienta la principal Base Naval Argentina. Esto refuerza la idea que los destinos turísticos maduros tienden a transformarse en ciudades con dinámicas de desarrollo urbano que superan las propias del turismo.

Pinamar y Villa Gesell conforman un clúster especial donde también se pueden visualizar algunos cambios. La TFT presenta una disminución respecto al 2001. Por otro lado, mientras la VP también ha disminuido, el IE es el más bajo de todos, lo que demuestra que estas ciudades tienden a concentrar una población joven y activa (el IA e IO han crecido). En cuanto al IH es el más alto y esto puede deberse a que son localidades balnearias cercanas al mayor centro emisor del país - el área metropolitana de Buenos Aires - razón por la cual muestran un mayor aumento en construcción y atracción de población y están más afectadas por procesos de desconcentración desde la ciudad capital.

Por último, el clúster 4 presenta un leve aumento en su condición turística. Esto se visualiza en el incremento de su TFT, la disminución de VP y del IH y un aumento del IE, IA e IO.

\subsection{Tipificación de las ciudades según su evolución turística y crecimiento urbano}

A partir del análisis realizado para cada año censal se propone una clasificación de las ciudades que integran los municipios costeros, basada en su evolución (Figura 4 y Tabla 5).

\section{Tabla 5 \\ TIPIFICACIÓN DE LA EVOLUCIÓN DE LAS CIUDADES DE LOS MUNICIPIOS LITORALES DE LA PROVINCIA DE BUENOS AIRES (2001-2010)}

\begin{tabular}{|l|l|l|}
\hline TIPO & $\begin{array}{l}\text { CIUDAD/ES } \\
\text { QUE INTEGRA }\end{array}$ & DESCRIPCIÓN \\
\hline $\begin{array}{l}\text { Ciudades no } \\
\text { turísticas }\end{array}$ & $\begin{array}{l}\text { Cabildo } \\
\text { Coronel Dorrego } \\
\text { Comandante } \\
\text { Otamendi } \\
\text { Coronel Vidal } \\
\text { General Pirán } \\
\text { Juan Fernández } \\
\text { Tres Arroyos } \\
\text { San Cayetano }\end{array}$ & $\begin{array}{l}\text { Está integrado exclusivamente por ciudades no turísticas } \\
\text { durante todo el período. Todas son localidades de } \\
\text { interior. } \\
\text { Se ve un retroceso en su crecimiento poblacional } \\
\text { dándose casos de VP negativa. Además se observa un } \\
\text { aumento del IE que indica el incremento de la población } \\
\text { inactiva, lo que provoca un menor IA en 2010. }\end{array}$ \\
\hline
\end{tabular}




\begin{tabular}{|c|c|c|}
\hline $\begin{array}{l}\text { Ciudades con } \\
\text { actividad turística } \\
\text { que presentan un } \\
\text { intenso crecimiento } \\
\text { urbano }\end{array}$ & $\begin{array}{l}\text { Bahía Blanca } \\
\text { Mar del Plata } \\
\text { Necochea } \\
\text { Orense } \\
\text { Punta Alta }\end{array}$ & $\begin{array}{l}\text { Integra a ciudades que han presentado un gran } \\
\text { crecimiento urbano a partir del turismo. } \\
\text { Bahía Blanca y Punta Alta, son ciudades multisectoriales } \\
\text { donde la actividad económica no depende de un solo } \\
\text { factor. } \\
\text { Mar del Plata es una localidad turística costera que } \\
\text { ha pasado de ser un destino turístico a contener una } \\
\text { importante actividad comercial, portuaria, pesquera e } \\
\text { industrial, además de poseer más de medio millón de } \\
\text { habitantes. } \\
\text { Necochea y Orense son localidades costeras donde el } \\
\text { turismo se ha convertido en un factor relevante para } \\
\text { su desarrollo económico, aunque en Necochea se } \\
\text { complementa con la actividad portuaria y la industria } \\
\text { agroalimentaria y en Orense con la agropecuaria. } \\
\text { En este grupo de ciudades el turismo tiene una influencia } \\
\text { media, un crecimiento poblacional estable, una población } \\
\text { relativamente vieja, con un IA importante. Por otro lado, } \\
\text { presentan un IH bajo lo que permite deducir que hay } \\
\text { una buena calidad de vida y mayor igualdad entre las } \\
\text { condiciones habitacionales. }\end{array}$ \\
\hline $\begin{array}{l}\text { Ciudades de } \\
\text { servicio }\end{array}$ & Batán & $\begin{array}{l}\text { Se caracteriza por ser una ciudad joven, con un alto } \\
\text { IH y una importante actividad laboral. Su cercanía } \\
\text { con Mar del Plata provoca que aun sin ser turística, } \\
\text { su funcionalidad esté relacionada con el turismo. Esto } \\
\text { es así debido a que alberga una importante cantidad } \\
\text { de población y empresas, que se ocupan de atender } \\
\text { necesidades de Mar del Plata, y con mayor intensidad en } \\
\text { temporadas turísticas. }\end{array}$ \\
\hline $\begin{array}{l}\text { Ciudades turísticas } \\
\text { con intenso } \\
\text { crecimiento urbano }\end{array}$ & $\begin{array}{l}\text { Pinamar } \\
\text { Villa Gesell }\end{array}$ & $\begin{array}{l}\text { Se caracterizan por tener una evolución urbana que } \\
\text { se explica exclusivamente a partir del turismo. Si } \\
\text { bien presentan la TFT más baja del grupo de ciudades } \\
\text { turísticas, el turismo es una actividad influyente, ya que } \\
\text { por cada residente existen tres turistas que vacacionan en } \\
\text { el lugar. Presentan un aumento del IH, que es el más alto } \\
\text { de todos los grupos observados. Esto está relacionado } \\
\text { con el auge de la construcción durante los años } \\
\text { analizados y con el aumento de su población, aunque } \\
\text { no con una mejora de las condiciones habitacionales, } \\
\text { generando además, una mayor desigualdad poblacional. } \\
\text { Ambos son destinos que se fueron desarrollando como } \\
\text { satélites de Mar del Plata. Su cercanía a la capital del país } \\
\text { ha provocado un crecimiento acelerado convirtiéndose a } \\
\text { lo largo de los años en destinos de playa cada vez más } \\
\text { importantes. Presentan un gran incremento del IA y una } \\
\text { evolución hacia una población más joven. }\end{array}$ \\
\hline
\end{tabular}




\begin{tabular}{|l|l|l|}
\hline $\begin{array}{l}\text { Ciudades turísticas } \\
\text { con crecimiento } \\
\text { estable }\end{array}$ & $\begin{array}{l}\text { Miramar } \\
\text { San Clemente del } \\
\text { Tuyu } \\
\text { Santa Clara del } \\
\text { Mar } \\
\text { Santa Teresita }\end{array}$ & $\begin{array}{l}\text { Se diferencian de las del grupo anterior por tener la } \\
\text { TFT más alta, lo que implica una mayor influencia de la } \\
\text { actividad turística. Su principal característica es que se } \\
\text { trata de ciudades que se han mantenido estables en torno } \\
\text { a su única actividad económica, el turismo. } \\
\text { Si bien tienen un gran crecimiento poblacional, se puede } \\
\text { observar un retroceso en su crecimiento y el menor } \\
\text { IH. Este hecho es congruente con un menor desarrollo } \\
\text { de la construcción en relación al resto de las ciudades } \\
\text { turísticas, además de demostrar una mejor calidad de } \\
\text { vida. Presentan un IA que a pesar de ir en incremento } \\
\text { respecto al período anterior, es el más bajo de los grupos. } \\
\text { Estas ciudades se caracterizan por ser destinos turísticos } \\
\text { costeros satélites de un destino principal: Miramar y } \\
\text { Santa Clara del Mar de Mar del Plata; y las dos restantes } \\
\text { de Pinamar. }\end{array}$ \\
\hline $\begin{array}{l}\text { Ciudades con } \\
\text { mayor intensidad } \\
\text { de crecimiento } \\
\text { turístico }\end{array}$ & $\begin{array}{l}\text { Las Toninas } \\
\text { Mar de Ajo } \\
\text { Monte Hermoso. }\end{array}$ & $\begin{array}{l}\text { Son las ciudades que han evolucionado de manera } \\
\text { más intensa en torno al turismo, presentando el mayor } \\
\text { desarrollo de la provincia. Así lo demuestra su TFT } \\
\text { promedio. Se caracterizan por tener un gran crecimiento } \\
\text { poblacional, sobresaliendo Las Toninas. Cuentan con } \\
\text { una comunidad relativamente joven y activa y con un IH } \\
\text { importante relacionado con el auge de la construcción, } \\
\text { principalmente de viviendas de segunda residencia. } \\
\text { Son ciudades balnearias que presentan una alta } \\
\text { estacionalidad de la demanda y su funcionalidad está } \\
\text { relacionada exclusivamente con la actividad turística. }\end{array}$ \\
\hline
\end{tabular}

Fuente: Elaboración propia. 


\section{Figura 4 \\ MAPA DE TIPOLOGÍA DE LA EVOLUCIÓN DE LAS CIUDADES DE LOS MUNICIPIOS LITORALES DE LA PROVINCIA DE BUENOS AIRES \\ (2001-2010)}

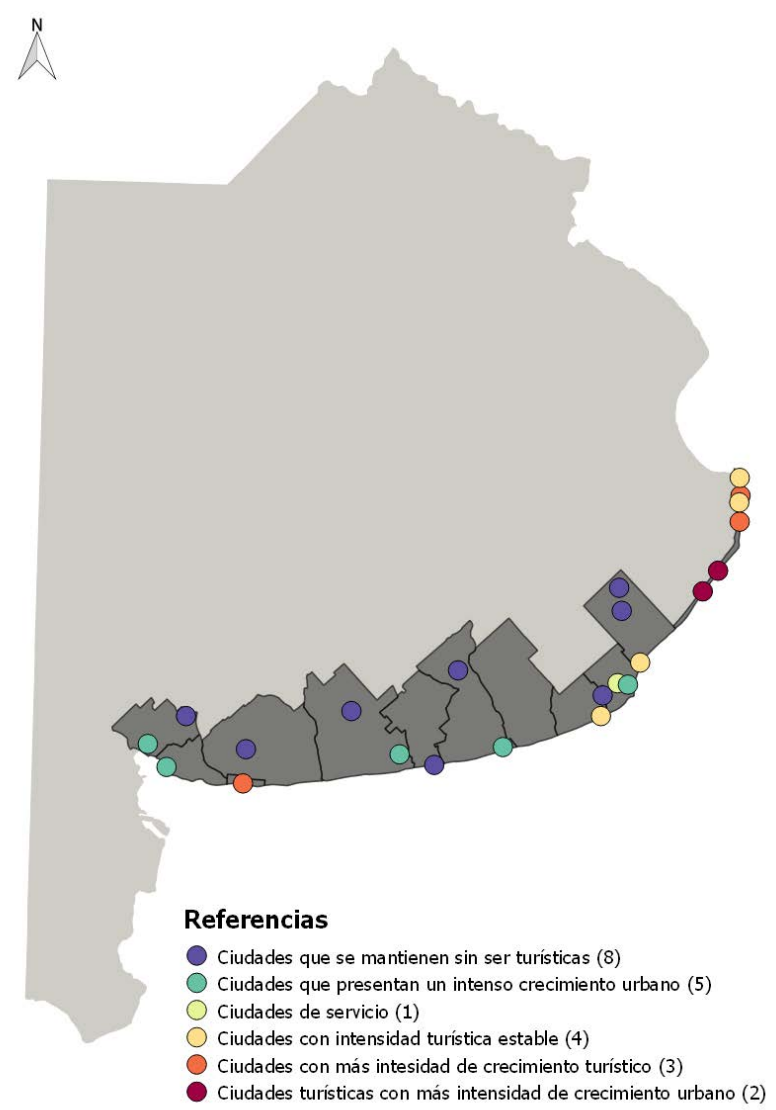

Fuente: Elaboración propia.

Nota: se define la cantidad de ciudades que integra cada tipología

\section{DISCUSIONES Y CONCLUSIONES}

Dado que el presente trabajo busca analizar las dinámicas de urbanización que se producen en los municipios costeros de la Provincia de Buenos Aires y, en base a las evidencias empíricas obtenidas, abundar en el conocimiento del turismo como factor de crecimiento y transformación de las ciudades y de los sistemas urbanos, se discute a continuación acerca de las principales cuestiones que pueden ser tenidas en consideración tanto desde las perspectivas de las dinámicas sociales globales que propician el fenómeno 
observado como desde la perspectiva de las características endógenas y la identidad de las comunidades locales dónde se localizan.

Los resultados obtenidos a partir del análisis empírico permiten introducir nuevos elementos en el análisis del papel del turismo en el crecimiento urbano en los municipios costeros de la Provincia de Buenos Aires y, por ende, en la reflexión acerca de los efectos del desarrollo turístico en la dinámica urbana, especialmente en el contexto latinoamericano. Ello es relevante en la medida que hasta el momento este tipo de análisis se han realizado mayoritariamente en otros contextos políticos y económicos (Mullins, 1991; Essex y Brown, 1997; Williams y Hall, 2000; Gu y Wall, 2007; González Reverté, 2008; Holderbaun y Lemos, 2012).

Así, se ha podido reflexionar sobre los aportes teóricos más relevantes del proceso de urbanización turística en América Latina, que se relacionan con el dinamismo económico (Valdivieso y Coll-Hurtado, 2010; Mendoza y Leal, 2010), el crecimiento demográfico (Anaya y Palafox, 2007; Lozano y Ramírez, 2007; Calderon y Orozco, 2009; Boggio Vázquez, 2008), el incremento de oportunidades laborales y la localización de nuevos residentes en ciudades turísticas generando un efecto migratorio (Mantero, 2002; Merlotto, 2010) y la existencia de problemas de rebasamiento de la capacidad de carga social, crecimiento excesivo y falta de infraestructura (Fonseca y Costa, 2004; Soares y Gandara, 2010; Padilla y Benseny, 2104).

Una segunda contribución que realiza esta investigación es de carácter metodológico a través de la conformación de conglomerados de ciudades que presentan pautas de evolución semejantes. Se han identificado seis grupos de ciudades según los procesos de cambio que ha provocado en ellas el turismo y se ha evidenciado la diversidad, complejidad y dinamismo que presenta cada tipo de conglomerado según sus características particulares. Todo ello, ha permitido realizar una reflexión general respecto al análisis de comprobación de las hipótesis planteadas. Estas ciudades presentan ciertas características distintivas que se aproximan a la definición de Mullins (1991) de ciudad turística en tanto que, siendo atractivas para los turistas han generado un rápido crecimiento de la población y de la fuerza laboral, que es flexible, además de poseer una estructura de grupos sociales específica y una organización residencial diferente.

En términos generales, se puede mencionar que las ciudades del litoral bonaerense presentan una alta tasa de función turística que van desde 2,95 a 7,66. Asimismo se ha podido deducir que las ciudades turísticas presentan un mayor crecimiento poblacional que las no turísticas y además se confirman que suelen agrupar a la población más joven y activa si se comparan con las no turísticas. Por otro lado, se puede observar que las ciudades turísticas tienden a presentar mayores problemas de hacinamiento poblacional que las no turísticas. Esta situación puede explicarse a partir de la atracción de nuevos residentes que inician su residencia en el destino de una manera precaria. En cuanto a la generación y el crecimiento de empleo, si bien los resultados demuestran que las localidades turísticas presentan un mayor incremento de actividad, en el análisis de la evolución del destino se puede observar que a medida que se consolidan disminuye su tasa de función turística. Ello implica una dinámica evolutiva en la que, a pesar de que el turismo sea una actividad que genera crecimiento a partir de un determinado momento aparecen otras actividades que contribuyen a su desarrollo. 
Más específicamente, se puede destacar que las ciudades que presentan un mayor crecimiento urbano, son ciudades donde la actividad económica no depende de un solo factor, aunque el turismo haya sido históricamente el fundamental; como es el caso de Mar del Plata pero también Pinamar y Villa Gesel. Estas dos últimas ciudades reflejan los problemas característicos del aumento de su población de forma rápida y espontánea como es la falta de buenas condiciones habitacionales, generando además, una mayor desigualdad poblacional. Tal como se ha apuntado en la revisión bibliográfica inicial, esta situación había sido observada ya en otras ciudades en las que el turismo ha transformado el espacio de manera radical debido a los efectos en cadena que ocasionó la migración, el crecimiento urbano, la expropiación de tierras, el impacto ambiental y la segregación social (Valenzuela Valdivieso E.y Coll-Hurtado A., 2010).

Un ámbito de discusión específico tiene que ver con las ciudades que han desarrollado formas de turismo residenciado - como son los casos de Las Toninas, Mar de Ajo y Monte Hermoso. Este tipo de turismo suele potenciar el auge de la construcción, principalmente de viviendas de segunda residencia, lo que conlleva a impactos positivos - económicos principalmente- pero también negativos. Se trata de una tipología de turismo cuyos efectos han sido especialmente estudiados en el ámbito mediterráneo español en relación a demanda vacacional europea y de las propias áreas metropolitanas del país que, para el caso de las ciudades turísticas analizadas, se relaciona directamente con su cercanía a la metrópoli de Buenos Aires. Así, en el caso español Huete et al. (2008) se indica que tales dinámicas suelen ocasionar efectos negativos como desorden urbanístico, incesante construcción de viviendas y masificación, que pueden perjudicar la vida social. En este mismo sentido Vera Rebollo et al. (2005) afirma que el desarrollo de las actividades turísticas residenciales, aunque es evidente que contribuye con la generación del empleo y la renta, ocasiona importantes desajustes y desequilibrios funcionales, territoriales y medioambientales generados por el crecimiento desordenado. Tales cuestiones se observan en el caso del litoral bonaerense a través del indicador de Índice de Hacinamiento.

Por último, es interesante destacar que también, tal como ocurre en el litoral mediterráneo español (González Reverté, 2008), el proceso de urbanización observado es un fenómeno asimétrico que no se produce de manera homogénea, sino que se distinguen sectores con diferentes dinámicas y potencialidades. Tal como apuntan Gu y Wall (2007), la atracción turística como factor de desarrollo urbano, genera dinámicas diferenciadas y competitivas, en las que los planificadores urbanos deben tomar un nuevo rol de administradores y facilitadores de proyectos, y mediar entre los diferentes conflictos de interés. Además, tal como lo menciona Anton Clavé et al. (2011), en determinados casos los destinos turísticos pueden dejar de ser entendidos como ciudades creadas solamente para la satisfacción de utilidades recreativas y ser consideradas como espacios urbanos genéricos.

Para concluir, se puede destacar que los resultados obtenidos permiten entender de manera contextualizada la naturaleza y funcionalidad turística y urbana de las diferentes ciudades del litoral de la provincia de Buenos Aires. Así, Mar del Plata no sólo es el destino turístico emblemático de la costa argentina, sino que fundamentalmente ha evolucionado hacia ciudad, en donde el turismo es una actividad más entre muchas otras. Que, de forma parecida, Pinamar y Villa Gesell son destinos que a pesar del desarrollo turístico se están convirtiendo en ciudades cada vez más multisectoriales. Batán, por su parte, surge 
como ciudad de servicios (a solo $30 \mathrm{~km}$ de la ciudad de Mar del Plata), demostrando, por lo tanto, que el turismo no sólo contribuye al crecimiento urbano de las ciudades donde se produce, sino también en localidades satélites. Por último, se encuentran casos como los de Monte Hermoso y Las Toninas que demuestran que existen destinos que aún se encuentran en fases primigenias de desarrollo turístico y urbano. Todo ello ha permitido visualizar la diversidad de destinos que existen en el litoral de la provincia Buenos Aires según su situación urbana particular y su evolución turística reciente.

\section{BIBLIOGRAFÍA}

ALMEIDA-GARCIA, F. y BALBUENA VÁZQUEZ, A. (2014): «Mar del Plata (Argentina) y Málaga (España). Estudio comparado de dos destinos turísticos». Pasos. Revista de Turismo y Patrimonio Cultural, vol. 12 (2), pp. 325-340.

ANAYA ORTIZ, J.S. y PALAFOX MUÑOZ, A (2007): «Reflexiones sobre la política turística y el desarrollo sustentable en la Isla de Cozumel», Teoría y Praxis, $\mathrm{n}^{\circ} 3$, pp. 153-160.

ANTON CLAVÉ, S. (1997): Diferenciació i reestructuració de l'espai turístic. Processos $i$ tendències al litoral de Tarragona. Universitat Rovira i Virgili.

ANTON CLAVÉ, S. (2012): «Rethinking mass tourism, space and place», en The Routledge Handbook of Tourism Geographies. Londres, Routledge, pp. 217-224.

ANTON CLAVÉ, S.; SALAMANCA, O.R. y REBOLLO VERA, J.F. (2011): «Mass Tourism Development on the Mediterranean Coast», Tourism Geographies, vol. 13 (3), pp. 495-501.

BENSENY, G. (2011): «La valorización turística de la costa atlántica. El surgimiento de Villa Gesell, Argentina», Aportes y Transferencias, vol. 15 (2), pp. 70-102.

BERTONCELLO, R. (1992): Configuración socio-espacial de los balnearios del Partido de la Costa (Provincia de Buenos Aires). Instituto de Geografía, Facultad de Filosofía y Letras, Universidad de Buenos Aires.

BLÁZQUEZ, M. y CAÑADA, E (2011): «Turismo Placebo. Nueva colonización turística: del Mediterráneo a Mesoamérica y El Caribe. Lógicas espaciales del capital turístico», El Periplo Sustentable, n 20, pp. 187-193.

BROUDER, P.; ANTON CLAVÉ, S.; GILL, A. y IOANNIDES, D. (2017): «Why is tourism not an evolutionary science?» en: P. BROUDER, S. ANTON CLAVÉ, A. M. GILL Y D. IOANNIDES (Eds.), Tourism Destination Evolution. Routledge, London, pp. 1-18.

BOSMAN, C.; DEDEKORKUT HOWES, A. y LEACH, A. (2016) (Ed.): Off the Plan: the urbanisation of the Gold Coast. CSIRO PUBLISHING.

BOUVET, Y., DESSE, R.P., MORELL, P. y VILLAR, M.C. (2005): «Mar del Plata (Argentina): la ciudad balnearia de los porteños en el Atlántico suroccidental», Investigaciones Geográficas, n ${ }^{\circ}$ 36, pp. 61-80.

CALDERÓN MAYA, J.R. y OROZCO HERNÁNDEZ, M.E (2009): «Planeación y modelo urbano: el caso de Cancún, Quintana Roo», Quivera Revista de Estudios Territoriales, vol. 11 (2), pp. 18-34. 
CAMPODÓNICO, R. y CUNHA, N. (2009): «Mar del Plata y Punta del Este. Entre la permanencia y la renovación», Estudios y Perspectivas en Turismo, vol. 18 (5), pp. 603-623.

CASADO DÍAZ, M.A.; KAISER, C. y WARNES, A.M. (2004): «Northern European retired residents in nine southern European areas: characteristics, motivations and adjustment», Ageing \& Society, vol. 24 (3), pp. 353-381.

CLIVAZ, C., CREVOISIER, O., KEBIR, L. NAHRATH, S. y SOTCK M. (2014): “The circulation of wealth resort development and Touristic capital of place", MAPS - Maison d'analyse des processus sociaux. vol. 5, pp. 1-25.

DE RIVERA, I.; SALVADÓ, N.; ANTON, S.; LORENZO, D.; LORENZO, D.; BENEDETTA, R.; SALVADÓ, T. y SAUQUET, R. (2015): «Escenarios de regeneración urbana en un entorno turístico costero del litoral mediterráneo, la Av. Carles Buigas de Salou». International Conference on Regional Science. Disponible en: https://old. reunionesdeestudiosregionales.org/Reus2015/htdocs/pdf/p1527.pdf

EQUIPE, M.I.T.; PARIS, F. y DUHAMEL, P. (2008): Tourismes 1: lieux communs. Belin.

ESSEX, S.J. y BROWN, G.P. (1997): «The emergence of post-suburban landscapes on the north coast of New South Wales: a case study of contested space», International Journal of Urban and Regional Research, vol. 21 (2), pp. 259-287.

FERNANDES CAMPOS, D. y BEZERRA MAIA., D.N. (2015): «Factores de atractividad y calidad de los Servicios turísticos en el destino Pipa-Brasil», Estudios y Perspectivas en Turismo», vol. 24 (2), pp. 205-221.

FERNANDEZ, M.R. (2015): «Costas, mercancías y derechos: hacia un paradigma sustentable del turismo costero », Alba sud. vol 17.

FERRÁN ARANAZ, M. (1996): SPSS para Windows: Programación y análisis estadístico (No. 310/F37s).

FONSECA, M.A.P. y COSTA, A.A. (2004): «A Racionalidade da urbanizacao turística em áreas deprimidas: o espaço produzido para o visitante (rationality of touristic urbanisation in depressed zones: the specific space for visitors) », Mercator, vol. 3 , no 6, pp. 25-32.

GLADSTONE, D.L. (1998): «Tourism urbanization in the United States», Urban Affairs Review, vol. 34 (1), pp. 3-27.

GONZÁLEZ REVERTÉ, F. (2008): «El papel de los destinos turísticos en la transformación sociodemográfica del litoral mediterráneo español», Boletín de la Asociación de Geógrafos Españoles, no 47, pp. 79-107.

GONZALEZ REVERTÉ, F.; ROMERO PADILLAY.; MURO MORALES J. I.; NAVARRO JURADO E. y GOMIS LOPEZ J. M. (2014): «La creatividad en las cuidades turísticas del sistema urbano mediterráneo español. Un análisis comparado». Espacios turísticos e inteligencia territorial: respuestas ante la crisis: actas del coloquio, pp. 197-214. Red de Impresión.

GU, K. y WALL, G. (2007): « Rapid urbanization in a transitional economy in China: the case of Hainan Island», Singapore Journal of Tropical Geography, vol. 28, no 2, pp. $158-170$.

HOLDERBAUM, B.S.; OLAGUE DE LA CRUZ, J.T. y SILVA LEMOS, A. (2012): «El nivel de calidad de núcleos turísticos urbanizados del turismo de masa y la propuesta 
de ciudad turística. El caso de la urbanización El Veril (Gran Canaria) España», Estudios y Perspectivas en Turismo, vol. 21 (6), pp. 1.336-1,368.

HUETE, R., MANTECÓN, A. y MAZÓN, T. (2008): «¿De qué hablamos cuando hablamos de turismo residencial? », Cuadernos de Turismo, $\mathrm{n}^{\circ}$ 22, pp. 101-121.

INDEC, Instituto Nacional de Estadística y Censos (1991 - 2001 - 2010). Censo Nacional de Población, Hogares y Viviendas. Disponible en:https://www.indec.gob.ar/.

LOZANO CORTÉS, M. y LORÍA RAMÍREZ A. (2007): «El impacto de las políticas de planificación regional en el desarrollo del Caribe mexicano», Teoría y Praxis, $\mathrm{n}^{\circ} 3$, pp. 43-52.

MAFFIONI, J.; BERTONI, M. y FAGINAS, V.L. (2016): «La calidad ambiental en Necochea: las innovaciones en la gestión y las certificaciones turísticas», FACES, vol. 22 (46), pp. 63-79.

MANTERO, J.C. (1997): «Mar del Plata: devenir urbano y desarrollo turístico», FACES, vol. 3 (4), pp. 135-152.

MANTERO, J.C. (2002): «Turismo y ambiente: centros turísticos del litoral atlántico. Diagnosis y proposición». En Ocio y desarrollo personal. Enfoques y perspectivas II, pp. 51-71.

MENDOZA ONTIVEROS, M. y LEAL TORRES, S.E. (2010): «Turismo en Playa del Carmen México. Impactos socio culturales en la Colonia Colosio», Estudios y Perspectivas en Turismo, vol. 19 (5), pp. 850-865.

MERLOTTO, A. y VERÓN, E.M. (2010): «Calidad de vida de los partidos costeros de la Provincia de Buenos Aires, Argentina», Geográfica Digital, vol. 7 (13), pp. 1-12.

MULLINS, P. (1991): «Tourism urbanization», International Journal of Urban and Regional Research, vol. 15 (3), pp. 326-342.

MULLINS, P. (1992): «Cities for pleasure: The emergence of tourism urbanization in Australia», Built Environment, vol. 18 (3), pp. 187-198.

OLANO POZO, J.X. (2019): Qui viu a les destinacions turístiques i per què? Anàlisi de l'atracció de treballadors creatius i de Baixa especialització en les destinacions dels sistema urbà català. Tarragona, Universitat Rovira i Virgili. Tesis Doctoral.

OLANO POZO, J.X.; GONZÁLEZ, F. y ANTON CLAVÉ, S. (2017): «Consideraciones sobre l'atracció de residentes a les destinacions turístiques catalanes: El cas dels treballadors creatius», Revista Económica de Catalunya, nº 76, pp. 74-85.

PADILLA, N.A y BENSENY, G. (2014): «Análisis del paisaje costero de Santa Clara del Mar, Argentina», Geografía Digital, vol. 11 (21), pp. 1-11.

QUESADA ARAMBURÚ, J. y CADELLI, E. (2012): Hacia una clasificación de los municipios bonaerenses. Documento de Trabajo DPEPE, $\mathrm{n}^{\circ} 04$.

SANZ IBÁÑEZ, C. y ANTON CLAVÉ, S. (2014): «The evolution of destinations: towards an evolutionary and relational economic geography approach», Tourism Geographies, vol. 16 (4), pp. 563-579.

SOARES, J. y GANDARA, J. M. (2010): «La Evolución de los Destinos Turísticos Litorales Consolidados y Estrategias para su Renovación: Un Análisis de Florianópolis-SC (BRASIL) ». En Anales del XIII Congreso Internacional de Turismo Universidad y Empresa: renovación de destinos turísticos consolidados. pp. 113-136. 
STOCK, M. (2015): “Habiter comme «faire avec l'espace». Réflexions à partir des théories de la pratique", Annales de Géographie, n 4, pp. 424-441.

ROVIERA SOTO, M. y ANTÓN CLAVÉ, S. (2018): «The role of second homes in a Mediterranean coastal mass tourism destination: An evolutionary perspective». The Routledge Handbook of Second Home Tourism and Mobilities. Routledge, pp. 45-56.

VALDIVIESO, E. y COLL HURTADO, A. (2010): «La construcción y evolución del espacio turístico de Acapulco (México), Anales de Geografía de la Universidad Complutense, vol. 30 (1), pp. 163-190.

VÁZQUEZ, J.B. (2008): «Planeación estratégica para el desarrollo: el caso de Quintana Roo», Teoría y Praxis, $\mathrm{n}^{\circ}$ 5, pp. 69-84.

VERA REBOLLO, J.F. (2005): «El auge de la función residencial en destinos turísticos del litoral mediterráneo: entre el crecimiento y la renovación». Papers de Turisme, $\mathrm{n}^{\circ}$ 37- 38, pp. 95-114.

WILLIAMS, A.M. y HALL, C.M. (2000): «Tourism and migration: new relationships between production and consumption», Tourism Geographies, vol. 2 (1), pp. 5-27. 